\title{
Oral Mucosal Lesions and Adverse Habits Among Hospitalized Tuberculosis Patients of Udaipur, Rajasthan, India
}

\author{
Mridula Tak, ${ }^{1,}$ Kushal Shinde, ${ }^{1}$ Nagesh Bhat, ${ }^{1}$ Kailash Asawa, ${ }^{1}$ Anukriti Singh, ${ }^{1}$ and Sandeep Jain ${ }^{1}$ \\ ${ }^{1}$ Department of Public Health Dentistry, Pacific Dental College and Hospital, PAHER University, Udaipur, India \\ "Corresponding author: Mridula Tak, Department of Public Health Dentistry, Pacific Dental College and Hospital, PAHER University, Udaipur, India. Tel: +91-9928840140, E-mail: \\ mtak1084@gmail.com
}

Received 2015 July 09; Revised 2015 October 06; Accepted 2015 November 14.

\begin{abstract}
Background: There is a dearth of epidemiologic studies that provide important information to understand the incidence, prevalence and severity of oral lesions in patients with tuberculosis (TB).

Objectives: This study aimed to determine the prevalence of oral mucosal lesions and adverse habits among hospitalized TB patients.

Patients and Methods: The study was conducted on all the TB patients $(n=118)$ admitted to the Tuberculosis and chest diseases Sanitarium in Udaipur City, Rajasthan, India, during April-May 2014. Oral mucosal lesions along with adverse habits were assessed according to world health organization,1980. Demographic characteristics of the subjects were recorded. Data were analyzed using the chi-square.

Results: The prevalence of oral mucosal lesions and adverse habits among study population accounted for $58.4 \%$ and $95 \%$ respectively. Among all the habits, bidi smoking was most prevalent (30.5\%), followed by habits in combination (23.7\%). Oral lesions were found to be significantly highest among those who were on combination of habits and also among those who were suffering from the habit for more than 10 years duration.

Conclusions: The findings of the current study indicate a high prevalence of oral mucosal lesions and adverse habits among the patients with TB disease. Hence, there is an urgent need of probing this public health problem by the health authorities.
\end{abstract}

Keywords: Habits, Mouth Mucosa, Pathology, Tuberculosis

\section{Background}

Tuberculosis (TB), the second driving reason for mortality due to infectious diseases worldwide accounted for 9 million new cases in 2013 and 1.5 million deaths as reported under WHO global Tuberculosis report 2014. India alone carries a burden of $24 \%$ of the world's episode cases with the most affected age group being 25-54 years (1).

Tuberculosis is an irresistible sickness brought on by the bacillus Mycobacterium tuberculosis. It normally influences the lungs (aspiratory TB) yet can influence different locales too (extrapulmonary TB). The disease spreads in the air when people who are sick with pulmonary TB expel bacteria, for example by coughing (1). In India, TB is for the most part an ailment of poor. The majority of its victims are migrant laborers, slum dwellers, residents of backwards areas and tribal pockets. Poor living conditions, lack of healthy sustenance, shanty lodging and congestion are the principle purposes behind the spread of the illness (2). Different components that build the danger of creating TB are diabetes, interminable lung ailment, liquor addiction and overwhelming tobacco utilization. These inclining conditions are identified with reduction in ability to create and keep up T-cell intervened resistance against the irresistible specialists (3). Tobacco and liquor utilization have been built up as danger components for the development of premalignant and malignant lesions of the oral mucosa. Pros reported distinctive lesions in association with tobacco use, for instance, leukoplakia, smoker's melanosis, and oral sub mucous fibrosis (4).

Selvamuthukumar SC (2011) determined that 14 regular oral lesions were observed among TB patients including oral submucous fibrosis, leukoplakia, oral lichen planus, aphthous ulcer, etc. It was estimated that the oral manifestations of lesions can produce distinct pattern of oral findings in TB group of patients (5). There is some evidence of oral manifestations of $\mathrm{TB}$, which have focused mainly on the rare lesions caused by M. tuberculosis (6). However, only few studies $(5,7)$ have focused on the status of oral lesions in this target group.

\section{Objectives}

Since tobacco and alcohol use are associated with TB as well as oral lesions, and epidemiological data of oral mucosal lesions in patients with TB is lacking, this study was 
conducted to determine the prevalence of oral mucosal lesions in relation to habits among hospitalized patients with TB in Udaipur city, Rajasthan, India.

\section{Patients and Methods}

\subsection{Study Design, Study Setting, and Study Population}

A descriptive cross-sectional study was conducted on all $(n=118)$ the TB patients admitted to Tuberculosis and Chest Diseases Sanitarium in Udaipur city, Rajasthan, India, during April-May 2014. This TB Sanitarium is the only sanitarium of the district where TB patients are admitted. Of the total 118 subjects who participated in the survey, 102 (86.4\%) were males and 16 (13.6\%) were females. Majority of population was in 27-36 years age group $(n=43$, $36.4 \%$ ). Candidiasis was most commonly observed on the lateral part of tongue. Lichen Planus was seen on buccal mucosa. For oral submucous fibrosis buccal mucosa and pterygomandibular plica were commonly involved. Apthous ulcers were commonly found in lips, cheeks and floor of the mouth. Candidiasis was most commonly seen in the tongue region.

\subsection{Informed Consent, Ethical Clearance, Official Permission}

Informed consent for a noninvasive oral examination and for recording their adverse habits was obtained from the patients who were included in the study. Ethical clearance was obtained from the ethical clearance committee of pacific dental college and hospital, Udaipur city and the recording number is $\mathrm{PDCH} / 14 /$ EC-01. A written permission was obtained from the superintendent of the sanitarium before commencement of this survey.

\subsection{Training and Calibration}

Before the commencement of the study, the examiner was standardized and calibrated in the department of public health dentistry by the senior faculty member (professor and head) to ensure uniform interpretation, understanding and application of the codes and criteria for diseases to be observed and recorded and for consistent examination. The examiner first practiced the examination on a group of 10 subjects with a wide range of levels of disease conditions. Then the examiner applied the diagnostic criteria by examining a group of 20 subjects, with a full range of disease condition, twice on successive days. The intra examiner reliability for the diagnosis of oral mucosal lesions (world health organization (WHO), 1980) (8) was assessed using Kappa statistics, which was found to be $94 \%$.

\subsection{Inclusion Criteria Subjects}

willing to participate and suffering from TB were included in the study.

\subsection{Exclusion Criteria}

Subjects with other chest diseases and other systemic diseases, uncooperative patients, and those who were severely disabled were excluded from the study.

\subsection{Proforma Details}

The proforma was designed to assess the oral mucosal lesions according to WHO assessment form for oral mucosal disease, 1980 (8). Demographic details of subjects were recorded.

\subsubsection{Data Collection}

The examination was conducted in a well-lighted room attached with the ward in the sanitarium with the patient sitting on a portable chair facing natural light. Universal precautions according to center for disease control and prevention guidelines were followed. Plane mouth mirrors, disposable masks, disposable gloves, gauze pieces, cotton swabs, disinfecting solution were the examination tools. Sufficient numbers of sterilized instruments were carried for the examination to avoid any interruption during the study.

\subsection{Statistical Analysis}

The collected data were entered into the computer, and frequency tables were generated using statistical package for the social sciences version 17.0 software (SPSS Inc., Chicago, Illinois, USA). The chi-square test was used for statistical analysis. The confidence level and level of significance were set at $95 \%$ and 5\%, respectively.

\section{Results}

Table 1 shows the distribution of study subjects by age, gender and adverse habits. From a total of 118 subjects who participated in the survey, $102(86.4 \%)$ were males and 16 (13.6\%) were females. Majority of population was in 27-36 years age group $(n=43,36.4 \%)$. Among all the habits, bidi smoking was most prevalent (30.5\%), followed by habits in combination (23.7\%). Around 95\% of the study subjects were observed with adverse habits. Significantly $(P=0.02)$ a higher proportion of females (25\%) was observed without any adverse habits than males (1.9\%). However, the smokeless habit was more prevalent among females than males. Age group of 27-36 years demonstrated the lowest proportion of subjects (2.3\%) with no adverse habits.

Table 2 depicts comparative assessment of oral mucosal lesions by age and gender. The overall prevalence of oral mucosal lesions in study population was found to be $58.4 \%$. Age and gender comparison revealed that leukoplakia showed a significantly higher prevalence in 
Table 1. Distribution of Study Population by Age, Gender and Adverse Habits

\begin{tabular}{|c|c|c|c|c|c|c|c|c|c|c|c|}
\hline Variables & \multicolumn{9}{|c|}{ Adverse Habits n (\%) } & \multirow[t]{3}{*}{ No Habits } & \multirow[t]{3}{*}{ Total } \\
\hline & \multicolumn{5}{|c|}{ Smoking Tobacco } & \multicolumn{2}{|c|}{ Smokeless Tobacco } & \multirow[t]{2}{*}{ Other(Alcohol) } & \multirow[t]{2}{*}{ Combination of Habits } & & \\
\hline & Cigarette & Cigar & Water Pipe & European Pipe & Bidi & Arecanut & Tobacco & & & & \\
\hline \multicolumn{12}{|l|}{ Gender } \\
\hline Male & $4(3.9)$ & 0 & $3(2.9)$ & 0 & $34(33.3)$ & $6(5.8)$ & $10(9.8)$ & $15(14.7)$ & $28(27.4)$ & $2(1.9)$ & $102(86.4)$ \\
\hline Female & o & 0 & 0 & 0 & $2(12.5)$ & $6(37.5)$ & $4(25)$ & 0 & 0 & $4(25)$ & $16(13.6)$ \\
\hline \multicolumn{12}{|l|}{ Age, $y$} \\
\hline $17-26$ & $2(7.4)$ & 0 & $1(3.7)$ & 0 & $7(25.9)$ & $3(11.1)$ & $4(14.8)$ & $2(7.4)$ & $6(22.2)$ & $2(7.4)$ & $27(22.8)$ \\
\hline $27-36$ & 0 & 0 & $1(2.3)$ & 0 & $1(30.2)$ & $5(11.6)$ & $5(11.6)$ & $7(16.2)$ & $11(25.5)$ & $1(2.3)$ & $43(36.4)$ \\
\hline $37-46$ & $1(4)$ & 0 & $1(4)$ & 0 & $5(20)$ & $3(12)$ & $2(8)$ & $3(12)$ & $9(36)$ & $1(4)$ & $25(21.1)$ \\
\hline $47-56$ & 0 & 0 & 0 & 0 & $4(36.3)$ & 0 & $3(27.2)$ & $2(18.1)$ & $1(9)$ & $1(9)$ & $11(9.3)$ \\
\hline$>56$ & $1(8.3)$ & 0 & 0 & 0 & $7(58.3)$ & $1(8.3)$ & 0 & $1(8.3)$ & $1(8.3)$ & $1(8.3)$ & $12(10.1)$ \\
\hline Total & $4(3.3)$ & 0 & $3(2.5)$ & 0 & $36(30.5)$ & $12(10.1)$ & 14 (11.8) & $15(12.7)$ & $28(23.7)$ & 6(5) & $118(100)$ \\
\hline
\end{tabular}

the range of 37-46 -year age group and among females. Other lesions including leukoedema, smoker's melanosis, chewer's mucosa, hairy tongue and smokeless keratosis were found to be prevalent among $34.7 \%$ of the subjects. The lesions including carcinoma, leukokeratosis nicotina palatine, herpetic gingivostomatitis, acute necrotizing gingivitis, cancrum oris were not observed among the study subjects.

Table 3 reveals the comparative assessment of oral mucosal lesions by adverse habits. Leukoplakia, candidiasis and other lesions were found to be significantly highest among subjects who were consuming both tobacco and alcohol in combination.

Table 4 shows the comparative assessment of oral mucosal lesions according to duration of adverse habits in which it was found that those who were having adverse habits for more than 10 years, leukoplakia, candidiasis and other lesions were found to be significantly most prevalent.

\section{Discussion}

Tuberculosis is still among the most life-undermining irresistible sicknesses, bringing about high mortality in adults (9). The reality of the matter is that the dental identification of M. tuberculosis has the capability of serving as an imperative guide in the first line of control for this hazardous and regularly lethal disease (10). Hence, the present study was conducted to assess the prevalence of adverse habits and oral mucosal lesions among patients with TB.

Gender distribution in the present study population revealed a higher percentage of males $(n=102,86.4 \%)$ than females ( $n=16,13.6 \%$ ), which is higher than other study conducted in Brazil among patients with TB in the year 2013 (7). Most of the subjects (30.5\%) were addicted to bidi smoking habit, followed by habits in combinations, which is in accordance with the study conducted by Bhatnagar et al. among North Indian population (11). Among the smokeless habit group, tobacco chewing was most prevalent (11.8\%). The prevalence of alcohol consumption (12.7\%) in the present study was similar when compared to the result of other study among Italian population (12). In the present study, the prevalence of adverse oral habits was found to be much higher among the 37-46 -year age group, which is in concordance with other studies among general populations conducted in India $(4,13)$. Males showed a greater prevalence of adverse oral habits as compared to females in this study, which confirms the findings of the previous studies $(14,15)$.

The overall prevalence of oral mucosal lesions in study population was found to be $58.4 \%$, which was higher than the study conducted by Santiago et al. (2013) among Brazilian patients with TB (0.8\%) (7) and Shivakumar et al. (2010) (16) among South Indian population (11.33\%). Kakisi et al. (2010) also reported $58 \%$ of patients with secondary manifestations (10). The difference in finding with previous studies can be explained by lowered host response and increased virulence caused due to TB among the present study participants. Mycobacteria are endowed with mechanisms through which they can evade the onslaught of host defense response (17). Sezer B et al. (2004) explained the improvement in oral lesions in TB patient on receipt of anti-TB therapy (18). Age and gender comparison reveals 
Table 2. Comparative Assessment of Oral Mucosal Lesions by Age and Gender

\begin{tabular}{|c|c|c|c|c|c|c|c|c|c|c|}
\hline \multirow[t]{2}{*}{ Oral Lesions } & \multicolumn{6}{|c|}{ Age Group (Years) n (\%) } & \multicolumn{3}{|c|}{ Gender n (\%) } & \multirow[t]{2}{*}{$\operatorname{Total}(\mathbf{n}=\mathbf{1 1 8}) \mathbf{n}(\%)$} \\
\hline & $17-26(n=27)$ & $27-36(n=43)$ & $37-46(n=25)$ & $47-56(n=11)$ & $>56(n=12)$ & p value & Male $(n=102)$ & Female $(n=16)$ & PValue $^{\mathrm{a}}$ & \\
\hline Leukoplakia & 0 & $5(11.6)$ & $5(20)$ & $1(9)$ & 0 & $0.001^{\mathrm{b}}$ & $8(7.8)$ & $3(18.7)$ & $0.001^{\mathrm{b}}$ & $11(9.3)$ \\
\hline Erythroplakia & 0 & 0 & $1(4)$ & 0 & 0 & 0.331 & $1(0.9)$ & 0 & 0.790 & $1(0.8)$ \\
\hline Lichen planus & 0 & $1(2.3)$ & 0 & $1(9)$ & 0 & 0.212 & $2(1.9)$ & 0 & 0.345 & $2(1.6)$ \\
\hline Oral submucousfibrosis & 0 & $1(2.3)$ & 0 & 0 & 0 & 0.331 & $1(0.9)$ & 0 & 0.999 & $1(0.8)$ \\
\hline Candidiasis & $4(14.8)$ & $10(23.2)$ & $4(16)$ & $1(9)$ & 0 & $0.001^{\mathrm{b}}$ & $16(15.6)$ & $3(18.7)$ & $0.001^{b}$ & $19(16.1)$ \\
\hline Recurrent apthae & 0 & $3(6.9)$ & $2(8)$ & $1(9)$ & 0 & $0.001^{\mathrm{b}}$ & $5(4.9)$ & $1(6.2)$ & $0.001^{b}$ & $6(5)$ \\
\hline Other lesions & $6(22.2)$ & $13(30.2)$ & $11(44)$ & $7(63.6)$ & $4(33.3)$ & $0.001^{\mathrm{b}}$ & $32(31.3)$ & $9(56.2)$ & $0.001^{\mathrm{b}}$ & $41(34.7)$ \\
\hline Total lesions & $6(22.2)$ & $31(72.1)$ & $20(80)$ & $7(63.6)$ & $4(33.3)$ & $0.001^{\mathrm{b}}$ & $60(58.8)$ & $9(56.2)$ & $0.001^{\mathrm{b}}$ & $69(58.4)$ \\
\hline
\end{tabular}

Table 3. Comparative Assessment of Oral Mucosal Lesions by Adverse Habits

\begin{tabular}{|c|c|c|c|c|c|c|c|}
\hline \multirow[t]{2}{*}{ Oral Lesions } & \multicolumn{6}{|c|}{ Adverse Habits n (\%) } & \multirow[t]{2}{*}{ Total $(\mathbf{n}=\mathbf{1 1 8})$} \\
\hline & $\begin{array}{l}\text { Smoking Tobacco } \\
\quad(\mathrm{n}=43)\end{array}$ & $\begin{array}{c}\text { Smokeless } \\
\text { Tobacco }(n=26)\end{array}$ & $\begin{array}{l}\text { Other (Alcohol) } \\
\quad(\mathbf{n}=\mathbf{1 5})\end{array}$ & $\begin{array}{l}\text { Combination of } \\
\text { Habits }(n=28)\end{array}$ & No Habits $(n=6)$ & P Value $^{\mathbf{a}}$ & \\
\hline Leukoplakia & $4(9.3)$ & $2(7.6)$ & 0 & $5(17.8)$ & 0 & $0.04^{\mathrm{b}}$ & $11(9.3)$ \\
\hline Erythroplakia & 0 & 0 & 0 & $1(3.5)$ & 0 & 0.18 & $1(0.8)$ \\
\hline Lichen planus & 0 & $1(3.8)$ & $1(6.6)$ & 0 & 0 & 0.11 & $2(1.6)$ \\
\hline $\begin{array}{l}\text { Oral submucous } \\
\text { fibrosis }\end{array}$ & 0 & $1(3.8)$ & 0 & 0 & 0 & 0.18 & $1(0.8)$ \\
\hline Candidiasis & $3(6.9)$ & $5(19.2)$ & $1(6.6)$ & $10(35.7)$ & 0 & $0.05^{\mathrm{b}}$ & $19(16.1)$ \\
\hline Recurrent apthae & $1(2.3)$ & 0 & $1(16.6)$ & $2(7.1)$ & $2(33.3)$ & 0.07 & $6(5)$ \\
\hline Other lesions & $18(41.8)$ & $9(34.6)$ & $3(20)$ & $9(32.1)$ & $2(4.8)$ & $0.02^{\mathrm{b}}$ & $41(34.7)$ \\
\hline Total lesions & $18(41.8)$ & $14(53.8)$ & $6(40)$ & $27(96.4)$ & $4(66.6)$ & - & $69(58.4)$ \\
\hline
\end{tabular}

${ }^{\mathrm{a}}$ Test applied: the chi-square test.

${ }^{\mathrm{b}} \mathrm{P} \leq 0.05$ was set as statistically significant.

that leukoplakia showed a significantly higher prevalence in the range of 37-46 years age group (20\%) and among females (18.7\%), which is in accordance with the study done by Mobeerik et al. (2009) among Saudi dental patients and higher than study conducted by SC Selvamuthukumar et al. (2011) among patients with TB $(5,19)$. When compared according to adverse habits, the participants in the present study who were addicted to combination of habits showed a highest prevalence of oral mucosal lesions (96.4\%), which is similar to the study conducted by Patil P et al. (2013) among Indian population (20). Similarly, Campisi and Margiotta (12) reported one of the highest incidences of leukoplakia in the population who drank alcohol along with the habit of smoking. Tobacco and alcohol in combination can act as synergistic risk factors as tobacco contains carcinogens and alcohol facilitates the entry of carcinogen into exposed cells and thus alters the oral epithelium and its metabolism (12). Around 65\% of TB patients with no adverse habits also suffered from oral lesions, which explain the independent effect of tubercle bacilli in causation of oral lesions.

According to duration of habits, it was found that those who were having adverse habits for more than 10 years, leukoplakia, candidiasis and other lesions were found to be significantly most prevalent. The significant effect of duration of habits on the development of oral lesions was also noted in the findings of the previous study (21).

The findings of the current study focus on the oral health care needs of patients with TB. Potent antitubercular drugs and the steps taken by health authorities would 
Table 4. Comparative Assessment of Oral Mucosal Lesions According to Duration of Adverse Habits

\begin{tabular}{|c|c|c|c|c|}
\hline \multirow[t]{2}{*}{ Oral Mucosal Lesions } & \multicolumn{4}{|c|}{ Duration of Habits n (\%) } \\
\hline & $<5$ Years $(n=31)$ & 5-10 Years $(n=32)$ & $>10$ Years $(n=49)$ & PValue $^{a}$ \\
\hline Leukoplakia (n = 11) & 0 & $4(12.5)$ & $7(14.2)$ & $0.04^{\mathrm{b}}$ \\
\hline Erythroplakia $(n=1)$ & 0 & 0 & $1(2)$ & 0.21 \\
\hline Lichen planus $(n=2)$ & 0 & 0 & $2(4)$ & 0.16 \\
\hline Candidiasis ( $(n=19)$ & $3(9.6)$ & $5(15.6)$ & $11(22.4)$ & $0.02^{\mathrm{b}}$ \\
\hline Recurrent apthae $(n=6)$ & $3(9.6)$ & $2(6.2)$ & $1(2)$ & 0.23 \\
\hline Other lesions $(n=41)$ & $7(22.5)$ & $12(37.5)$ & $22(44.8)$ & $0.03^{\mathrm{b}}$ \\
\hline Total lesions $(\mathrm{n}=69)$ & $9(29)$ & $19(59.3)$ & $41(83.6)$ & $0.02^{\mathrm{b}}$ \\
\hline
\end{tabular}

${ }^{\mathrm{a}}$ Test applied: thechi-square test.

${ }^{\mathrm{b}} \mathrm{P} \leq 0.05$ was set as statistically significant.

undeniably reduce the national burden of disease. However, the oral health care needs of these patients still remain an unanswered question. Hence, steps should be undertaken to have numerous oral health wings at the various hospitals, which exclusively render care for patients with TB to minimize the sufferings of these patients and enhance their oral health related quality of life.

\subsection{Conclusion}

Findings of the present study clearly indicate a high prevalence $(58.4 \%)$ of oral mucosal lesions and adverse habits (95\%) among the patients with TB. Hence, to counter all the woes caused by the disease, there is an urgent need for the oral health care providers to satisfy their oral health needs. Oral health care programs providing comprehensive oral health care and educational programs to combat adverse habits targeting this population group are warranted.

\section{Footnote}

Authors' Contribution: Study concept and design: Mridula Tak, Kushal Shinde, Nagesh Bhat, and Kailash Asawa; acquisition of data: Mridula Tak, Kushal Shinde, Anukriti Singh, and Sandeep Jain; analysis and interpretation of data: Mridula Tak, kushal Shinde, Nagesh Bhat, and Anukriti Singh; drafting of the manuscript: Mridula Tak, Kushal Shinde, and Anukriti Singh; critical revision of the manuscript for important intellectual content: Mridula Tak, Kushal Shinde, Nagesh Bhat, Kailash Asawa, Anukriti Singh, and Sandeep Jain; statistical analysis: Anukriti Singh, and Sandeep Jain; administrative, technical, and material support: Mridula Tak, Nagesh Bhat, and Kailash Asawa; study supervision: Mridula tak, Nagesh Bhat, and Kailash Asawa.

\section{References}

1. World Health Organization. Global Tuberculosis Report 2014. World Health Organization; 2014.

2. Park K. Park's textbook of preventive and social medicine. 2007

3. Kumar V, Abbas AK, Fausto N, Mitchell RN. Robbins Basic Pathology. 8 ed. Saunders Elsevier; 2007.

4. Sujatha D, Hebbar PB, Pai A. Prevalence and correlation of oral lesions among tobacco smokers, tobacco chewers, areca nut and alcohol users. Asian Pac J Cancer Prev. 2012;13(4):1633-7. [PubMed: 22799380].

5. Selvamuthukumar SC, Aswath N, Anand V. Pattern of oral lesions in tuberculosis patients: A cross-sectional study. J Indian Academy Oral Med Radiology. 2011;23(3):199.

6. Ferguson KA, McCormack DG. Tuberculosis involving the oral cavity. Can J Infect Dis. 1993;4(1):12-4. [PubMed: 22346412].

7. Santiago RA, Gueiros LA, Porter SR, Gomes VB, Ferrer I, Leao JC. Prevalence of oral lesions in Brazilian patients with tuberculosis. Indian J Dent Res. 2013;24(2):245-8. doi: 10.4103/0970-9290.116698. [PubMed: 23965456].

8. Kramer IR, Pindborg JJ, Bezroukov V, Infirri JS. Guide to epidemiology and diagnosis of oral mucosal diseases and conditions. World Health Organization. Community Dent Oral Epidemiol. 1980;8(1):1-26. [PubMed: 6929240].

9. World Health Organization. World health organization global tuberculosis control. Geneva: World Health Organization; 2008.

10. Kakisi OK, Kechagia AS, Kakisis IK, Rafailidis PI, Falagas ME. Tuberculosis of the oral cavity: a systematic review. EurJ Oral Sci. 2010;118(2):1039. doi: 10.1111/j.1600-0722.2010.00725.x. [PubMed: 20486998].

11. Bhatnagar P, Rai S, Bhatnagar G, Kaur M, Goel S, Prabhat M. Prevalence study of oral mucosal lesions, mucosal variants, and treatment required for patients reporting to a dental school in North India: In accordance with WHO guidelines. J Family Community Med. 2013;20(1):41-8. doi: 10.4103/2230-8229.108183. [PubMed: 23723730].

12. Campisi G, Margiotta V. Oral mucosal lesions and risk habits among men in an Italian study population.J Oral Pathol Med. 2001;30(1):22-8. [PubMed: 11140896].

13. Chandra P, Govindraju P. Prevalence of oral mucosal lesions among tobacco users. Oral Health Prev Dent. 2012;10(2):149-53. [PubMed: 22763594]. 
14. Rani M, Bonu S, Jha P, Nguyen SN, Jamjoum L. Tobacco use in India: prevalence and predictors of smoking and chewing in a national cross sectional household survey. Tob Control. 2003;12(4):4. [PubMed: 14660785].

15. Al-Attas SA, Ibrahim SS, Amer HA, Darwish Zel S, Hassan MH. Prevalence of potentially malignant oral mucosal lesions among tobacco users in Jeddah, Saudi Arabia. Asian Pac J Cancer Prev. 2014;15(2):75762. [PubMed: 24568491].

16. Shivakumar GC, Sahana S, Saha S. Prevalence and site distribution of oral mucosal lesions in patients attending outpatient clinics of oxford dental college, bangalore. J Indian Assoc Public Health Dent. 2010;15:69-73.

17. Raja A. Immunology of tuberculosis. Indian $J$ Med Res. 2004;120(4):213-32. [PubMed: 15520479].
18. Sezer B, Zeytinoglu M, Tuncay U, Unal T. Oral mucosal ulceration: a manifestation of previously undiagnosed pulmonary tuberculosis. $J$ Am Dent Assoc. 2004;135(3):336-40. [PubMed: 15058623].

19. Al-Mobeeriek A, AlDosari AM. Prevalence of oral lesions among Saudi dental patients. Ann Saudi Med. 2009;29(5):365-8. [PubMed: 19700894].

20. Patil PB, Bathi R, Chaudhari S. Prevalence of oral mucosal lesions in dental patients with tobacco smoking, chewing, and mixed habits: A cross-sectional study in South India. J Family Community Med. 2013;20(2):130-5. doi: 10.4103/2230-8229.114777. [PubMed: 23983566].

21. Aruna DS, Prasad KV, Shavi GR, Ariga J, Rajesh G, Krishna M. Retrospective study on risk habits among oral cancer patients in Karnataka Cancer Therapy and Research Institute, Hubli, India. Asian Pac J Cancer Prev. 2011;12(6):1561-6. [PubMed: 22126499]. 